\title{
Influence of ball milling on the sintering behaviour of $\mathrm{ZnO}$ powder
}

\author{
Y.W. Lao, S.T. Kuo, W.H. Tuan* \\ Department of Materials Science and Engineering, National Taiwan University, Taipei 10764, Taiwan \\ Received 11 October 2007; received in revised form 29 April 2008; accepted 17 June 2008
}

\begin{abstract}
A high purity $\mathrm{ZnO}$ powder was milled with either $\mathrm{YSZ}$ or $\mathrm{Al}_{2} \mathrm{O}_{3}$ balls. The weight losses of $\mathrm{YSZ}_{\text {and }} \mathrm{Al}_{2} \mathrm{O}_{3}$ balls after milling for $4 \mathrm{~h}$ are 10 and $40 \mathrm{ppm}$, respectively. The debris of the milling media acts as sintering aid to the $\mathrm{ZnO}$ powder. As a result, the grain size of the sintered $\mathrm{ZnO}$ specimens is reduced. The ratio of the grain boundary energy over surface energy is also decreased.
\end{abstract}

(C) 2008 Elsevier Ltd and Techna Group S.r.l. All rights reserved.

Keywords: A. Milling; B. Microstructure-final; D. ZnO

\section{Introduction}

Zinc oxide $(\mathrm{ZnO})$ is a potential material for many applications such as varistor, displays, gas sensors [1-3], etc. For each application, additives are needed to modify the defect concentration within the $\mathrm{ZnO}$ grains and/or the chemistry of grain boundary. In order to mix $\mathrm{ZnO}$ with the additives, a milling technique is usually employed. Yttria-stabilized $\mathrm{ZrO}_{2}$ (YSZ) and alumina $\left(\mathrm{Al}_{2} \mathrm{O}_{3}\right)$ balls are the most popular milling media. However, the milling process may also contaminate the powder.

The performance of $\mathrm{ZnO}$ is sensitive to the presence of some additives even when their amount is very low. For example, a very small amount, $500 \mathrm{ppm}$ of $\mathrm{Al}\left(\mathrm{NO}_{3}\right)_{3} \cdot 9 \mathrm{H}_{2} \mathrm{O}$, could increase the donor density and enhance the voltage-current nonlinearity [4]. An amount of $800 \mathrm{ppm}$ of $\mathrm{Ag}$ can increase the grain boundary resistance of $\mathrm{ZnO}$ by 35-fold [5]. Therefore, the performance of $\mathrm{ZnO}$-based components is sensitive to the processing environment. The effect of the milling media on the sintering behaviour of $\mathrm{ZnO}$ is investigated in the present study.

\section{Experimental procedures}

A high-purity $\mathrm{ZnO}$ powder (60 g), YSZ balls $(535.5 \mathrm{~g}$ ) or $\mathrm{Al}_{2} \mathrm{O}_{3}$ balls $(328.2 \mathrm{~g}$ ) with diameter of $10 \mathrm{~mm}$, polyester (PE) jar with internal volume of $600 \mathrm{~cm}^{3}$, and ethanol $\left(300 \mathrm{~cm}^{3}\right)$

\footnotetext{
* Corresponding author. Tel.: +886 23659800; fax: +886223634562.

E-mail address: tuan@ccms.ntu.edu.tw (W.H. Tuan).
}

were used in the milling experiment. The milling media filled half of the volume of the container. A turbo mixer (T2F Turbula, Willy A Bachofen AG, Switzerland) was used for milling. The weight loss of the media after $4 \mathrm{~h}$ milling was recorded. The same procedure was repeated for four times. After drying the slurry, the dried lumps passed a \#150 sieve to remove the agglomerates. Green compacts, $10 \mathrm{~mm}$ diameter and $3 \mathrm{~mm}$ thick, were prepared by uniaxial pressing at $50 \mathrm{MPa}$. Sintering was performed with a dilatometer or a box furnace. The heating rate was $5{ }^{\circ} \mathrm{C} / \mathrm{min}$. The cross-section of the specimens was ground with silicon carbide particles and polished with alumina particles. The grain boundaries were revealed by soaking the polished section in dilute hydrochloric acid. The microstructure was observed by using scanning electron microscopy (SEM). The SEM micrographs were then digitized by using a scanner. The image analysis was performed on the digitized images in order to determine the area of each grain. Over 500 grains were measured for each composition. The equivalent circular diameter was determined from the area, assuming that each grain was spherical. The mean grain size was calculated by multiplying the mean equivalent circular diameter by 1.5 .

\section{Results and discussion}

Table 1 shows the weight loss of the milling media after $4 \mathrm{~h}$ milling. The average weight loss of four test runs from the YSZ and $\mathrm{Al}_{2} \mathrm{O}_{3}$ balls is 10 and $40 \mathrm{ppm}$, respectively. Milling is a process involving complex mechanical forces. The weight loss from the $\mathrm{Al}_{2} \mathrm{O}_{3}$ balls after milling is four times that from the 
(a)

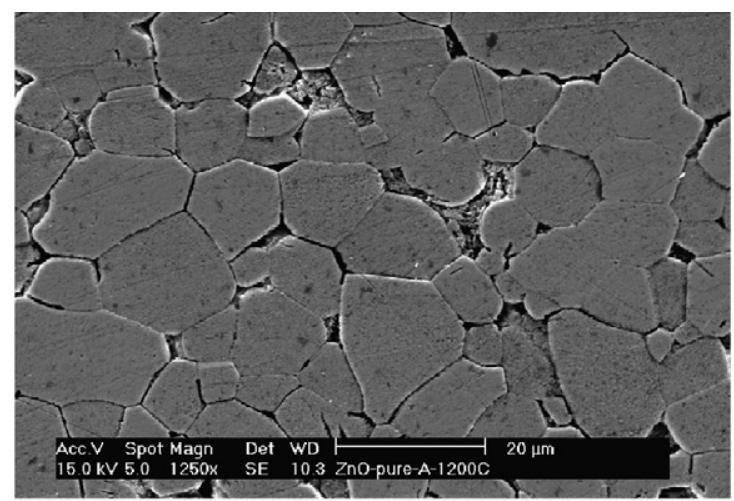

(b)

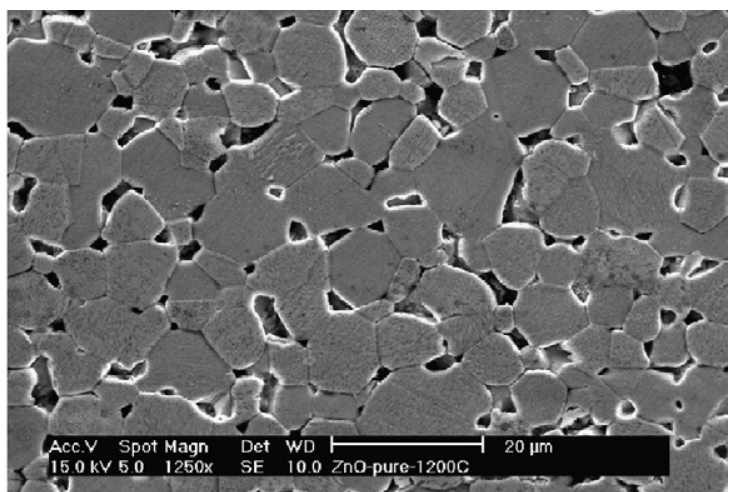

(c)

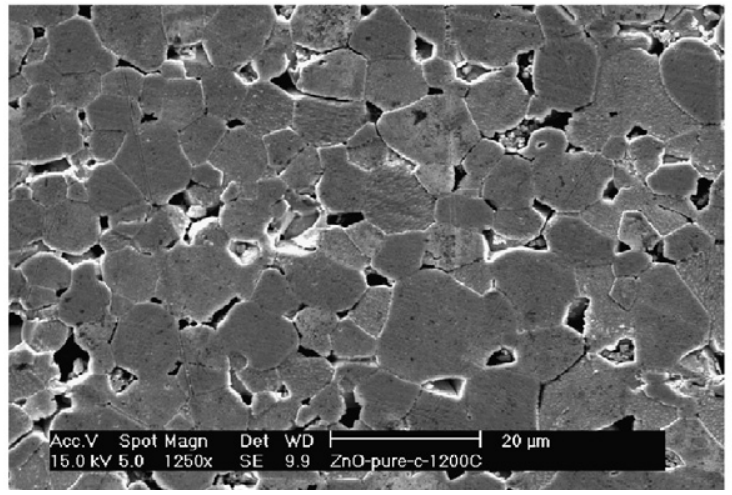

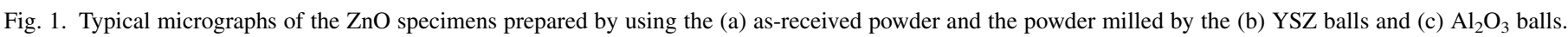

YSZ balls. Though the hardness of alumina is double that of the zirconia, the toughness of YSZ is double that of $\mathrm{Al}_{2} \mathrm{O}_{3}$ [6]. It suggests that the wear behaviour of the milling balls is dominated by brittle fracture. After milling, the wear debris would mix into the powder. The microstructure of the specimens is uniform after sintering, Fig. 1, implying that the mixing of the wear debris and $\mathrm{ZnO}$ particles is uniform. The milling process can thus be treated as a technique to mix a small amount of additive into powder.

The size of $\mathrm{ZnO}$ grains is the largest in the specimen prepared by using the as-received powder. The shape of pores in the specimen prepared by using the as-received powder is different from that of the pores in the ball-milled specimens. The size distribution of the $\mathrm{ZnO}$ grains is shown in Fig. 2. The curves follow roughly the log-normal distribution. The average grain size and size scattering in terms of standard deviation for

Table 1

Weight loss of milling media after milling with $\mathrm{ZnO}$ powder for $4 \mathrm{~h}$

\begin{tabular}{lcl}
\hline $\begin{array}{l}\text { Milling media } \\
\text { (no. of test) }\end{array}$ & $\begin{array}{l}\text { Weight } \\
\text { loss (ppm) }\end{array}$ & $\begin{array}{l}\text { Average weight } \\
\text { loss (ppm) }\end{array}$ \\
\hline YSZ (run 1) & 11.6 & \\
YSZ (run 2) & 9.0 & $10.4 \pm 1.1$ \\
YSZ (run 3) & 10.8 & \\
YSZ (run 4) & 10.1 & \\
$\mathrm{Al}_{2} \mathrm{O}_{3}$ (run 1) & 32.9 & $38.4 \pm 8.9$ \\
$\mathrm{Al}_{2} \mathrm{O}_{3}$ (run 2) & 51.5 & \\
$\mathrm{Al}_{2} \mathrm{O}_{3}$ (run 3) & 32.6 & \\
$\mathrm{Al}_{2} \mathrm{O}_{3}$ (run 4) & 36.6 &
\end{tabular}

the $\mathrm{ZnO}$ specimens are shown in Table 2. Though the average size of $\mathrm{ZnO}$ grains is different, the coefficient of variation (C.V.) for the size scattering is very close to each other.

The shrinkage rates of the powder compacts prepared by milling with YSZ and $\mathrm{Al}_{2} \mathrm{O}_{3}$ balls are shown in Fig. 3. The shrinkage rate of the compact prepared by using the as-received $\mathrm{ZnO}$ powder is also shown for comparison. The shrinkage of the powder compacts prepared by ball milling is slower than that of the as-received powder. Though the shrinkage rate curves are very similar to each other, there is a small hump observed in the curve for the specimens prepared by using the as-received powder. It indicates that there are two populations of pores present in the powder compacts; the small pores are at the intraagglomerated sites and large ones at inter-agglomerated site [7]. There is no small peak observed in the specimens prepared by using the milled powders, indicating that the agglomerates are destroyed during milling. The average grain size follows the same trend as that of the density. The grain size distribution

Table 2

Microstructure characteristics of $\mathrm{ZnO}$ specimens after sintering at $1200{ }^{\circ} \mathrm{C}$ for $1 \mathrm{~h}$

\begin{tabular}{lcll}
\hline & $\begin{array}{l}\text { Average grain } \\
\text { size }(\mu \mathrm{m})\end{array}$ & $\begin{array}{l}\text { Standard } \\
\text { deviation }(\mu \mathrm{m})\end{array}$ & C.V.* $(\%)$ \\
\hline As-received & 14.5 & 5.8 & 40 \\
YSZ milling media & 11.0 & 4.6 & 41 \\
$\mathrm{Al}_{2} \mathrm{O}_{3}$ milling media & 9.9 & 3.9 & 39
\end{tabular}

*Note: C.V. $=$ coefficient of variation $=($ standard deviation $) /($ average grain size). 
Y.W. Lao et al. / Ceramics International $x x x$ (2008) $x x x-x x x$

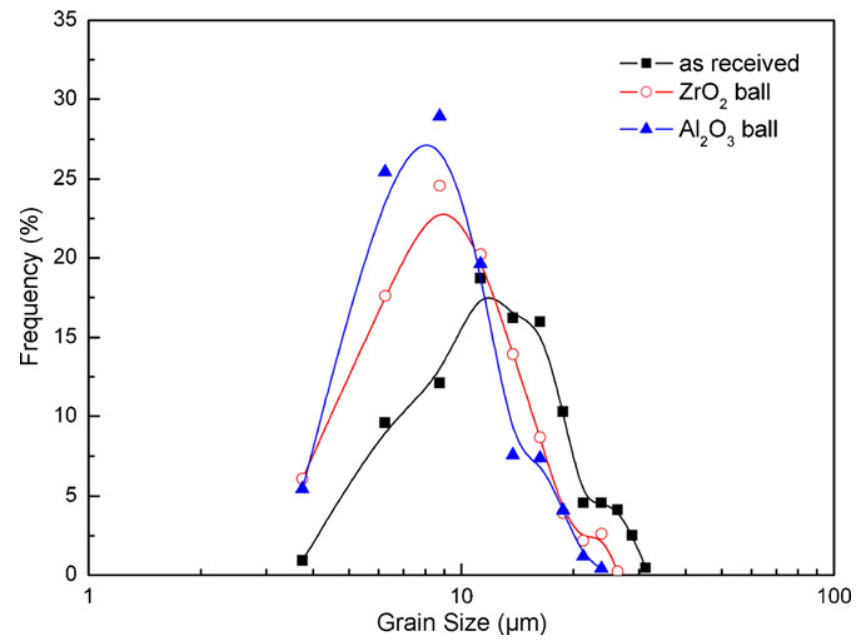

Fig. 2. Size distribution of $\mathrm{ZnO}$ grains in the $\mathrm{ZnO}$ specimens after sintering at $1200{ }^{\circ} \mathrm{C}$ for $1 \mathrm{~h}$

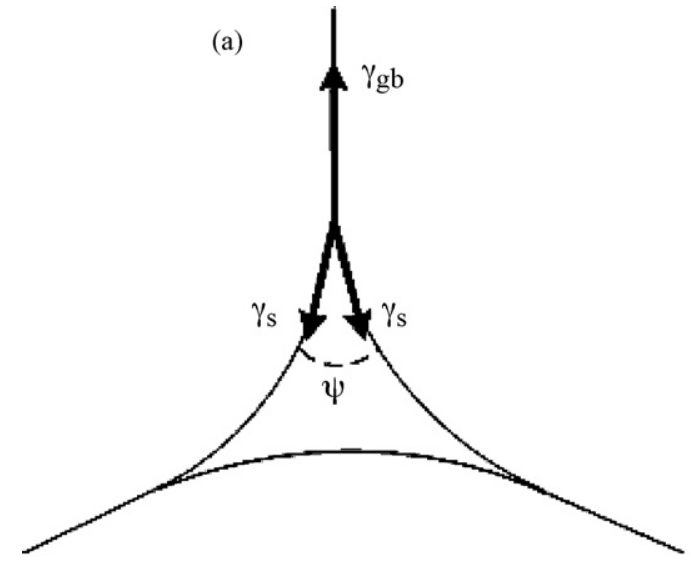

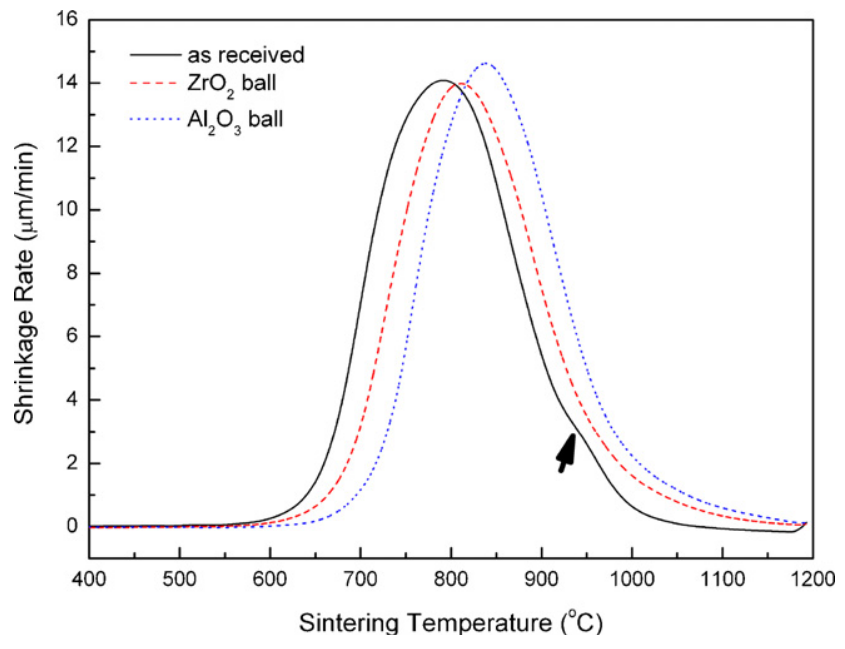

Fig. 3. Densification rate of the $\mathrm{ZnO}$ specimens as a function of temperature.

(b)

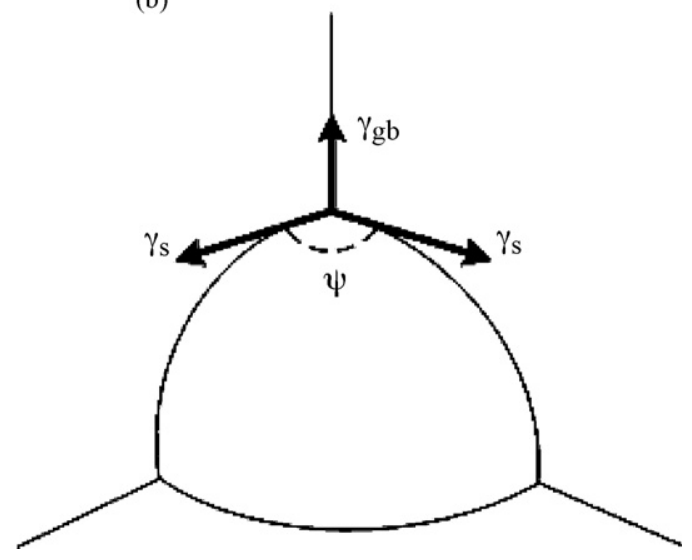

Fig. 4. Balance between surface energy $\left(\gamma_{\mathrm{s}}\right)$ and grain boundary energy $\left(\gamma_{\mathrm{gb}}\right)$ for (a) pure $\mathrm{ZnO}$ and (b) $\mathrm{ZrO}_{2}$ and $\mathrm{Al}_{2} \mathrm{O}_{3}$-doped $\mathrm{ZnO}$ specimens.

curves of the three specimens are very similar; furthermore, the pores are mainly located at the triple junctions and no pores trapped within the $\mathrm{ZnO}$ grains (Fig. 1). It indicates that the pores move with the grain boundaries during sintering. The growth of $\mathrm{ZnO}$ grains thus follows the trend of density increase.

It is worth noting that the pore shape is changed due to the addition of the $\mathrm{ZrO}_{2}$ and $\mathrm{Al}_{2} \mathrm{O}_{3}$ dopants. The dihedral angle of pure $\mathrm{ZnO}$ is usually small [8]. Many additives, such as $\mathrm{Bi}_{2} \mathrm{O}_{3}$, may increase the value of the dihedral angle. The value of the dihedral angle $(\psi)$ is the balance between grain boundary energy $\left(\gamma_{\mathrm{gb}}\right)$ and surface energy $\left(\gamma_{\mathrm{s}}\right)$ as

$\cos \frac{\psi}{2}=\frac{1}{2} \frac{\gamma_{\mathrm{gb}}}{\gamma_{\mathrm{s}}}$

The presence of $\mathrm{ZrO}_{2}$ and $\mathrm{Al}_{2} \mathrm{O}_{3}$ dopants may modify both grain boundary energy and surface energy to different extent. Since the dihedral angle is increased, this indicates that both the $\mathrm{ZrO}_{2}$ and $\mathrm{Al}_{2} \mathrm{O}_{3}$ additives reduce the ratio grain boundary energy/surface energy, as suggested in Fig. 4.

\section{Conclusions}

The densification and grain growth rates of $\mathrm{ZnO}$ are slowed down after milling with zirconia and alumina balls. The presence of zirconia and alumina milling debris can also reduce the dihedral angle; the densification and grain growth behaviour of $\mathrm{ZnO}$ are therefore affected.

\section{References}

[1] W.G. Carlson, T.K. Gupta, Improved varistor nonlinearity via donor impurity doping, J. Appl. Phys. 53 (8) (1982) 5746-5753.

[2] R. Ghosh, G.K. Paul, D. Basak, Effect of thermal annealing treatment on structural, electrical and optical properties of transparent sol-gel $\mathrm{ZnO}$ thin films, Mater. Res. Bull. 40 (11) (2005) 1905-1914.

[3] P. Nunes, E. Fortunato, P. Vilarinho, R. Martins, Effect of different dopants on the properties of $\mathrm{ZnO}$ thin films, Int. J. Inorg. Mater. 3 (2001) 12111213.

[4] J. Fan, R. Freer, The roles played by Ag and Al dopants in controlling the electrical properties of ZnO varistors, J. Appl. Phys. 77 (9) (1995) 4795 4800 . 
[5] S.T. Kuo, W.H. Tuan, J. Shieh, S.F. Wang, Effect of Ag on the microstructure and electrical properties of $\mathrm{ZnO}$, J. Eur. Ceram. Soc. 27 (16) (2007) 4521-4527.

[6] R. Morrell, Handbook of properties of technical \& engineering ceramics: Part 1, in: An Introduction for the Engineer and Designer, National Physical Lab, London HMSO, 1985.
[7] A. Roosen, H. Hausner, Sintering kinetics of $\mathrm{ZrO}_{2}$ powders, Adv. Ceram. 12 (1984) 714-726.

[8] J.-H. Choi, N.-M. Hwang, D.-Y. Kim, Pore-boundary separation behavior during sintering of pure and $\mathrm{Bi}_{2} \mathrm{O}_{3}$-doped Zno ceramics, J. Am. Ceram. Soc. 84 (6) (2001) 1398-1400.

Please cite this article in press as: Y.W. Lao, et al., Influence of ball milling on the sintering behaviour of ZnO powder, Ceram. Int. (2008), doi:10.1016/j.ceramint.2008.06.015 